\title{
Escala diagramática para avaliação da severidade da mancha de Phoma do cafeeiro
}

\author{
Mirian Salgado ${ }^{1}$, Edson A. Pozza ${ }^{1}$, Luciana Maria de Lima ${ }^{1}$, Ricardo T.G. Pereira ${ }^{2}$ \& Ludwig H. \\ Pfenning ${ }^{1}$
}

${ }^{1}$ Departamento de Fitopatologia, Universidade Federal de Lavras, 37200-000, Lavras, MG, Brasil; ${ }^{2}$ EMATER Minas Gerais, Escritório Regional Muriaé, 36880-000, Muriaé, MG, Brasil

Autor para Correspondência: Ludwig H. Pfenning, e-mail: ludwig@ufla.br

\begin{abstract}
RESUMO
Para avaliar a severidade da mancha de Phoma do cafeeiro (Phoma tarda) foi construída uma escala diagramática com oito níveis de severidade. A escala foi então validada por sete avaliadores. Quanto à precisão da escala, os valores de $\mathrm{R}^{2}$ variaram de 0,82 até 0,87 e de 0,85 até 0,94 sem e com o uso da escala, respectivamente. Os erros absolutos médios, severidade real menos a estimada, foram na maioria inferiores a 10\%. A escala apresentou boa acurácia com valores estimados de severidade próximos dos valores de severidade real. A reprodutibilidade dos valores estimados por avaliadores foi satisfatória, com valores de $\mathrm{R}^{2}$ superiores a 0,75 em todos os casos. A escala construída e validada pode ser considerada uma boa ferramenta para avaliar a severidade da mancha de Phoma, uma das mais importantes doenças do cafeeiro.
\end{abstract}

Palavras-chave: Coffea spp., patometria, epidemiologia, manejo de doenças de plantas, agricultura tropical.

\begin{abstract}
Diagrammatic scale to evaluate severity of phoma leaf blight of coffee trees

With the aim of offering an aid to evaluate disease severity of phoma leaf blight of coffee trees, a diagrammatic scale with eight levels of severity was developed. The scale was then validated by seven independent testers. As to the precision of the scale, $\mathrm{R}^{2}$ values varied between 0.82 and 0.87 , and 0.85 and 0.94 , with and without the use of the scale, respectively. The absolute average error, expressing the real severity minus the estimated severity, was mostly lower than $10 \%$. The scale evidenced good accuracy, with estimated values of severity close to the values of real severity. Reproducibility of the estimated values by the raters was satisfactory, with $\mathrm{R}^{2}$ values superior to 0.75 in all cases. This validated scale is a suitable tool for the evaluation of the severity of Phoma leaf blight, one of the most important diseases of the coffee tree.
\end{abstract}

Keywords: Coffea spp., pathometry, plant disease epidemiology, plant disease management, tropical agriculture.

A mancha de Phoma do cafeeiro ganhou importância em determinadas regiões produtoras de café, inclusive em viveiros, ocasionando lesões nas folhas e queda de frutos. O principal agente etiológico dessa doença é Phoma tarda (R.W. Stewart) H. Verm., embora outras espécies como $P$. exigua ou $P$. jolyana foram registradas em associação com o cafeeiro (Salgado \& Pfenning, 2000). Os sintomas da doença nas folhas são manchas irregulares de coloração escura, iniciando geralmente nos bordos. Além da redução da área foliar, o patógeno pode colonizar os ramos do cafeeiro e também as rosetas das gemas reprodutivas, causando queda de flores e frutos. Quando o patógeno ocorre em viveiros, pode causar a morte de plântulas. A doença é favorecida por temperaturas abaixo de $20^{\circ} \mathrm{C}$ e alta umidade relativa do ar (Salgado et al., 2002).

Apesar do registro de epidemias, poucos estudos relatam a relação entre a severidade da doença e as respectivas perdas. Sendo assim, são necessários métodos padronizados para avaliar a intensidade da doença, os quais devem ser simples, acurados, precisos e reprodutíveis (Horsfall \& Cowling, 1978; Madden et al., 2007). Na avaliação de doenças foliares do cafeeiro o uso de escalas diagramáticas já foi proposto para avaliações da severidade de doenças como a ferrugem e cercosporiose (Oliveira et al., 2001). Dessa forma, o objetivo do presente trabalho foi construir e validar uma escala diagramática para a avaliação da severidade da mancha de Phoma do cafeeiro.

Para elaborar a escala diagramática, foram coletadas 100 folhas em lavouras cafeeiras do sul de Minas Gerais, apresentando sintomas típicos da mancha de Phoma do cafeeiro. A identificação do fungo foi realizada utilizando literatura especializada (Stewart, 1957; Boerema et al., 2004). O patógeno foi caracterizado e identificado como Phoma tarda. As folhas com lesão foram colocadas sobre a leitora de um 'scanner' e as imagens foram digitalizadas na resolução de 300 dpi. A área foliar total e 
a área foliar lesionada de cada folha foram posteriormente determinadas utilizando o programa Image tool ${ }^{\circledR} 2002$. Após estabelecida a porcentagem de doença a ser representada na escala, de acordo com os níveis de maior ocorrência no campo, foram escolhidas imagens de folhas com áreas conhecidas para a construção da escala.

Para a validação da escala diagramática proposta, 55 folhas apresentando sintomas típicos de mancha de Phoma, com diferentes níveis de severidade foram coletadas no campo e tiveram sua área foliar total e necrosada determinadas conforme procedimento citado anteriormente. Imagens dessas folhas foram apresentadas a sete avaliadores sem experiência na avaliação da mancha de Phoma para estimar a severidade da doença. Inicialmente, a severidade foi estimada sem auxílio da escala diagramática e, sete dias após, com auxílio da mesma. Para avaliar a repetibilidade das estimativas com a escala diagramática, uma segunda estimativa foi efetuada sete dias após a primeira avaliação com auxílio da escala pelos mesmos avaliadores.

Os dados obtidos foram submetidos a análises estatísticas para determinar a acurácia, a precisão e a reprodutibilidade da escala (Nutter Junior \& Schultz, 1995). A acurácia foi avaliada aplicando-se o teste $t$ ao coeficiente angular (a) e ao coeficiente linear da reta (b) das equações obtidas para verificar se esses valores foram estatisticamente iguais a 1 (um) para " $b$ " e iguais a 0 para "a". A precisão da escala foi avaliada calculandose o coeficiente de determinação $\left(\mathrm{R}^{2}\right)$ da equação entre severidade real, utilizada como variável independente (x) e severidade estimada, utilizada como variável dependente (y), além da variância dos erros absolutos por avaliador, calculado subtraindo-se os valores de severidade real menos a estimada. A reprodutibilidade foi avaliada por meio da regressão linear entre valores estimados por avaliadores, sendo o valor de determinado avaliador a variável independente e de outro a variável independente. Para as análises de regressão utilizou-se o software estatístico SAS ${ }^{\circledR}$.

A mínima área foliar lesionada para escala diagramática proposta neste trabalho foi $1,3 \%$ e a máxima, de $50 \%$. Foi então construída a escala, com oito níveis de severidade, 1,$3 ; 2,5 ; 6,0 ; 7,5 ; 12 ; 20 ; 30$ e 50\% (Figura 1), seguindo a lei da acuidade visual de Weber-Fechner, conforme descrição de trabalho anterior em elaboração de escalas (Martins et al., 2004; Angelotti et al., 2009). Valores de severidade acima de $50 \%$ não foram incluídos na escala, pois, raramente são observados no campo devido à senescência das folhas.

Para a maioria dos avaliadores, os valores estimados deseveridadeficaram próximos dos valores de severidadereal (Tabela 1). Sem o uso da escala seis avaliadores apresentaram valores de coeficiente de linearidade (b) estatisticamente diferentes de zero no teste $t$ e quatro apresentaram valores de coeficiente angular (a), estatisticamente diferente de um. Esses avaliadores superestimaram a doença sem o uso da escala. Na primeira avaliação com o uso da escala, quatro avaliadores deixaram de superestimar a severidade da mancha de Phoma. Na segunda avaliação com a escala, quatro avaliadores apresentaram valores de coeficiente de linearidade (b) estatisticamente diferentes de zero no teste $\mathrm{t}$ e três apresentaram valores de coeficiente angular (a), estatisticamente diferente de um (Tabela 1). Assim, o treinamento dos avaliadores pode minimizar o problema da superestimativa da doença, inerente a muitos daqueles que trabalham com doenças de plantas (Nutter Junior \& Schultz, 1995; Godoy et al., 1997; Angelotti et al., 2009).

$\mathrm{Na}$ literatura não existem padrões de super ou subestimativa para a validação de escalas de doenças associadas a fungos necrotróficos. Por exemplo, para a cercosporiose da alface (Gomes et al., 2004) e cancro bacteriano da videira (Nascimento et al., 2005) houve superestimativa, enquanto para a mancha de alternaria do girassol e a cercosporiose do pimentão houve subestimativa (Leite \& Amorim, 2002; Michereff et al., 2006). Considerando estes valores, as estimativas dos avaliadores foram sistematicamente relacionadas com o valor real, de acordo com os critérios adotados em trabalhos com avaliação de escalas (Martins et al., 2004; Angelotti et al., 2009). Os avaliadores foram precisos quando avaliaram a severidade da mancha de Phoma sem o auxílio da escala, com coeficientes de determinação variando de 0,82 a 0,87 . Com o auxílio da escala, os avaliadores, melhoraram sua precisão, com coeficientes de determinação variando de 0,85 a 0,90 e 0,85 a 0,94 , na primeira e segunda avaliações, respectivamente (Tabela $1)$.

Houve redução dos erros absolutos para as estimativas com auxílio da escala diagramática, em relação à distribuição dos erros das estimativas obtidas sem o uso da escala. A maioria dos erros absolutos foi inferior a $10 \%$ quando os avaliadores utilizaram a escala para estimar a severidade da doença. Segundo critérios utilizados para avaliar escalas, baseados nos erros absolutos, valores inferiores a 5\% são considerados excelentes, enquanto até $10 \%$ são considerados bons (Nutter Junior \& Schultz, 1995). De acordo com estes critérios, a maioria dos avaliadores enquadra-se na faixa de excelente a bom (Figura 2).

Os coeficientes de determinação das equações de regressão linear calculados nas comparações das estimativas dos avaliadores entre si foram maiores com o uso da escala diagramática (Tabela 2). Assim, o uso da escala aumentou a reprodutibilidade das estimativas obtidas por diferentes avaliadores. Isso significa que a estimativa da severidade da doença realizada por qualquer avaliador fornecerá resultados semelhantes (Spósito et al., 2004). A escala construída e validada permite a avaliação da severidade da mancha de Phoma do cafeeiro e pode ser utilizada tanto na avaliação de experimentos como no monitoramento da doença no campo, além de padronizar a avaliação da severidade dessa doença. 


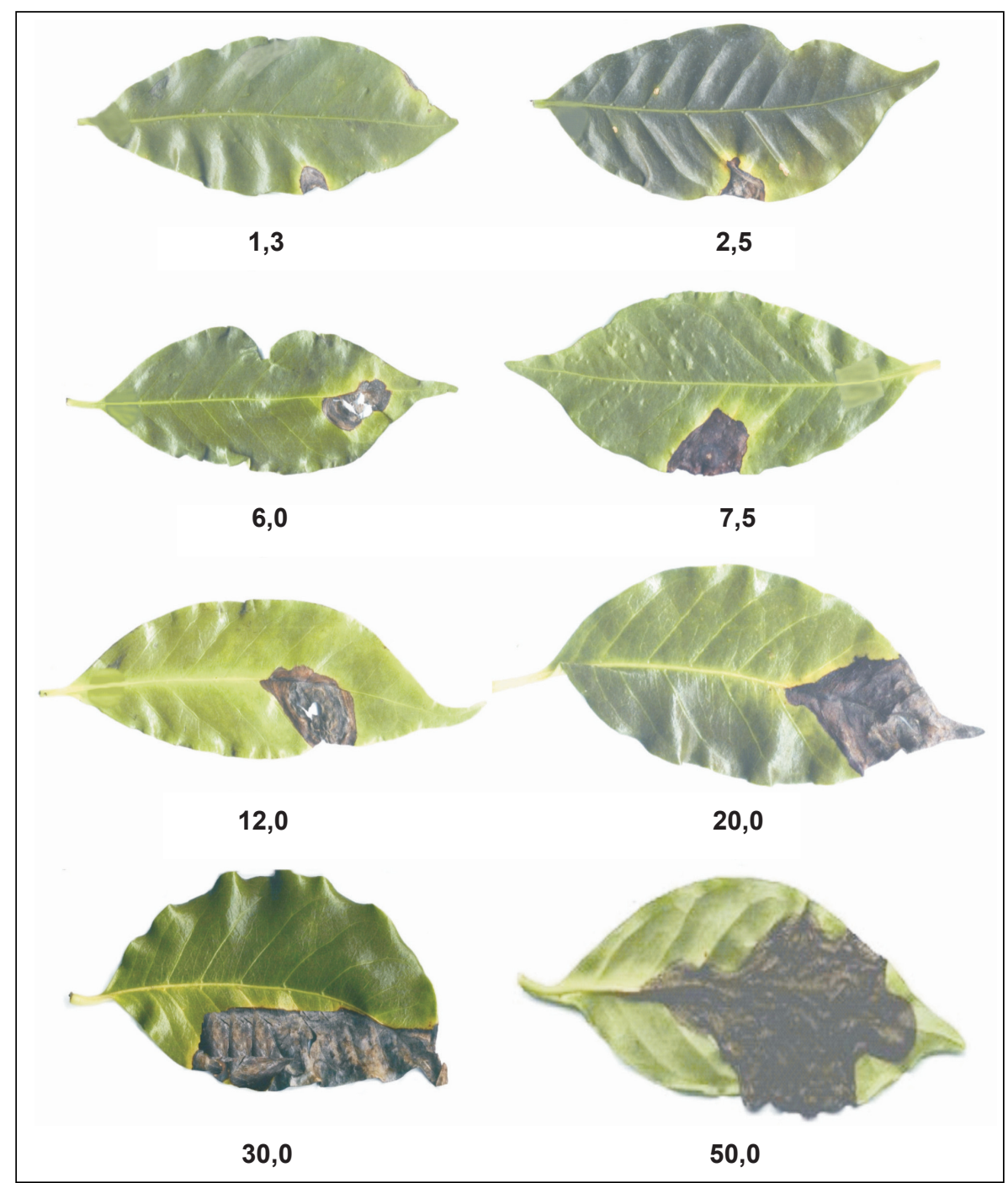

FIGURA 1 - Escala diagramática para avaliação da severidade de mancha de Phoma do cafeeiro (Phoma tarda). Os valores na escala indicam a porcentagem de área foliar lesionada.

TABELA 1 - Coeficiente de regressão e parâmetros $(y=a x+b)$ da equação ajustada entre a severidade real e a estimada, sem o uso da escala e na primeira e segunda avaliações com a escala diagramática

\begin{tabular}{cccccccccc}
\hline \hline \multirow{2}{*}{ Avaliador } & \multicolumn{3}{c}{ Sem o emprego da escala } & \multicolumn{3}{c}{ Primeira avaliação com a escala } & \multicolumn{3}{c}{ Segun da avaliação com a escala } \\
\cline { 2 - 10 } & $\mathbf{R}^{\mathbf{2}}$ & $\mathbf{a}$ & $\mathbf{b}$ & $\mathbf{R}^{\mathbf{2}}$ & $\mathbf{a}$ & $\mathbf{b}$ & $\mathbf{R}^{\mathbf{2}}$ & $\mathbf{a}$ & $\mathbf{b}$ \\
\hline 1 & 0,83 & $0,90^{*}$ & 0,26 & 0,88 & $0,82^{*}$ & 2,48 & 0,90 & $0,87^{*}$ & 2,74 \\
2 & 0,86 & 0,99 & $3,19^{*}$ & 0,87 & $0,88^{*}$ & 2,20 & 0,85 & $0,78^{*}$ & $3,97^{*}$ \\
3 & 0,87 & $0,79^{*}$ & $2,26^{*}$ & 0,86 & $0,76^{*}$ & $2,66^{*}$ & 0,88 & 0,91 & $0,88^{*}$ \\
4 & 0,83 & $0,87^{*}$ & $4,52^{*}$ & 0,83 & $0,85^{*}$ & $5,63 *$ & 0,93 & 1,00 & $5,94 *$ \\
5 & 0,86 & 1,09 & $4,77^{*}$ & 0,88 & 1,07 & $2,83 *$ & 0,92 & 0,91 & 2,33 \\
6 & 0,86 & $1,15^{*}$ & $3,83^{*}$ & 0,90 & 0,99 & $2,69 *$ & 0,94 & 1,03 & 2,08 \\
7 & 0,82 & 0,95 & $3,86^{*}$ & 0,89 & 0,93 & $3,30^{*}$ & 0,85 & $0,88^{*}$ & $5,04 *$ \\
\hline
\end{tabular}

* valores estatisticamente diferentes de 1 para coeficiente angular (a) e diferentes de 0 para coeficiente de linearidade (b) no teste "t" a $95 \%$ de confiança. 

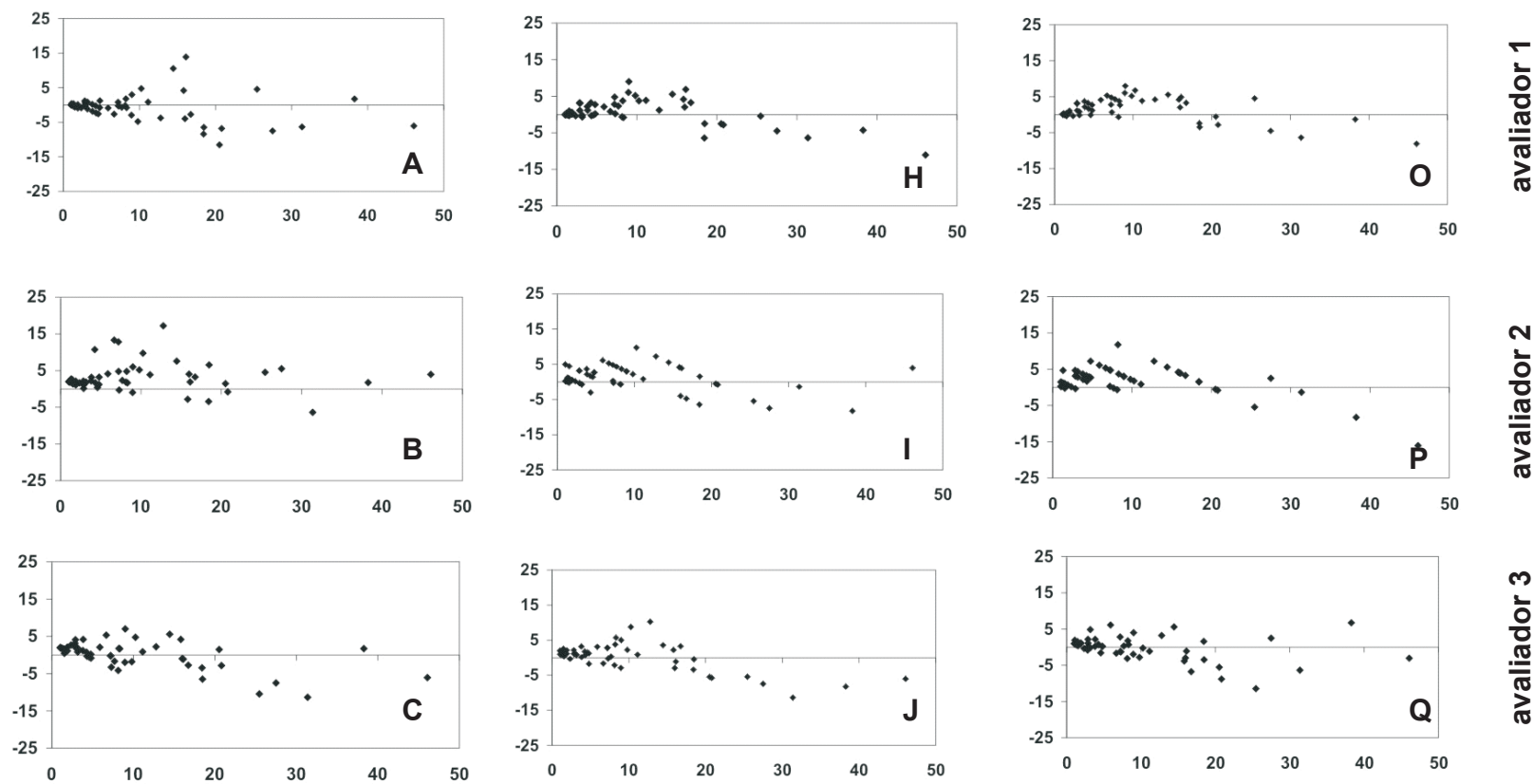

\section{$\frac{m}{\frac{0}{0}}$}
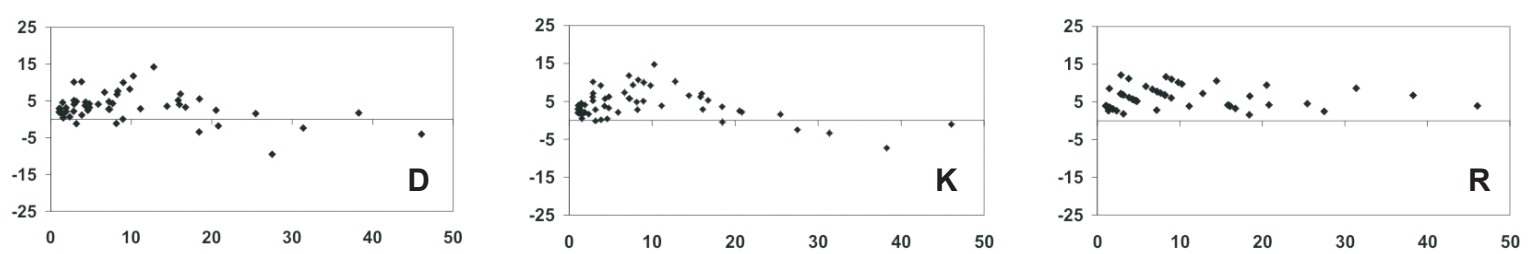

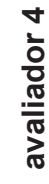
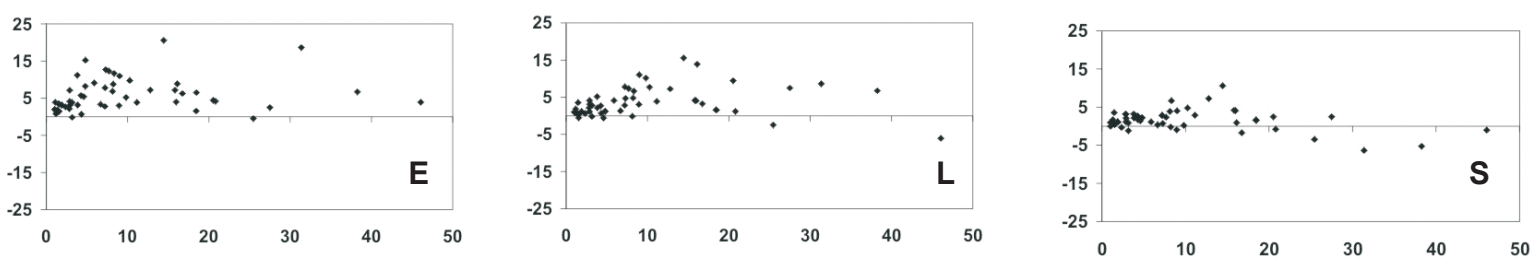

\section{옹}
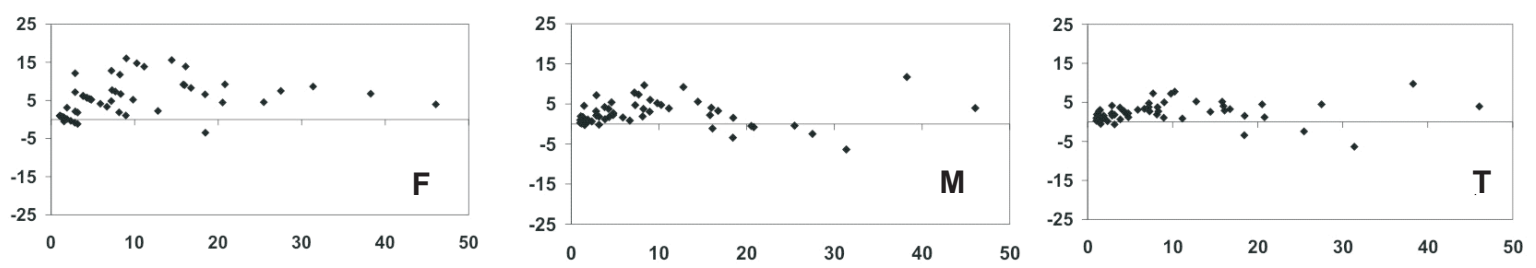

\section{$\frac{0}{\frac{1}{0}}$}
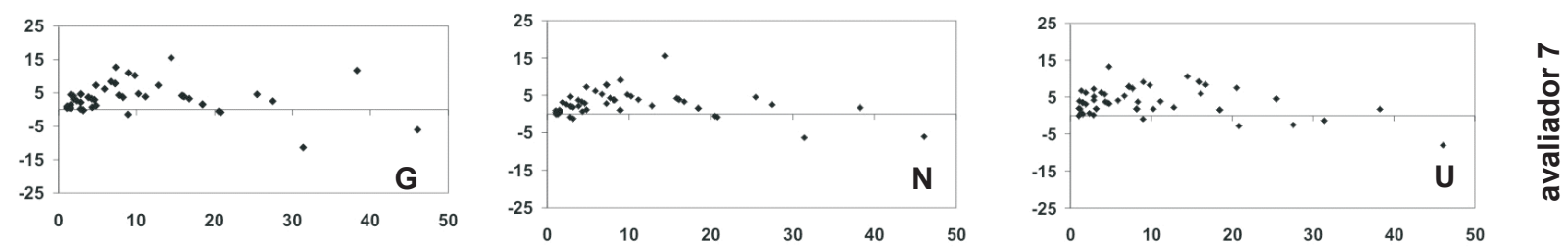

\section{Severidade (\%)}

FIGURA 2 - Erros absolutos (severidade real menos severidade estimada) das estimativas da severidade da mancha de Phoma do cafeeiro (Phoma tarda), por sete avaliadores com e sem o auxílio de escala diagramática. A-G: sem o uso da escala; H-N: $1^{\text {a }}$ avaliação com o uso da escala; O-U: $2^{\mathrm{a}}$ avaliação com o uso da escala. 
M. Salgado et al.

TABELA 2 - Coeficientes de determinação $\left(\mathrm{R}^{2}\right)$ de equações de regressão linear relacionando as estimativas da mancha de Phoma entre avaliadores sem e com auxílio da escala diagramática

\begin{tabular}{|c|c|c|c|c|c|c|}
\hline \multirow[b]{2}{*}{ Avaliador } & \multicolumn{5}{|c|}{ Sem a escala } & \multirow[b]{2}{*}{7} \\
\hline & 2 & 3 & 4 & 5 & 6 & \\
\hline 1 & 0,75 & 0,80 & 0,79 & 0,81 & 0,84 & 0,81 \\
\hline 2 & & 0,82 & 0,84 & 0,74 & 0,76 & 0,83 \\
\hline 3 & & & 0,83 & 0,77 & 0,83 & 0,85 \\
\hline 4 & & & & 0,83 & 0,83 & 0,82 \\
\hline 5 & & & & & 0,87 & 0,79 \\
\hline 6 & & & & & & 0,83 \\
\hline \multicolumn{7}{|c|}{ Primeira avaliação com a escala } \\
\hline Avaliador & 2 & 3 & 4 & 5 & 6 & 7 \\
\hline 1 & 0,83 & 0,86 & 0,86 & 0,92 & 0,87 & 0,92 \\
\hline 2 & & 0,88 & 0,85 & 0,82 & 0,84 & 0,81 \\
\hline 3 & & & 0,88 & 0,83 & 0,91 & 0,86 \\
\hline 4 & & & & 0,83 & 0,87 & 0,85 \\
\hline 5 & & & & & 0,84 & 0,89 \\
\hline 6 & & & & & & 0,88 \\
\hline \multicolumn{7}{|c|}{ Segunda avaliação com a escala } \\
\hline Avaliador & 2 & 3 & 4 & 5 & 6 & 7 \\
\hline 1 & 0,86 & 0,80 & 0,91 & 0,89 & 0,91 & 0,89 \\
\hline 2 & & 0,78 & 0,83 & 0,85 & 0,82 & 0,81 \\
\hline 3 & & & 0,84 & 0,86 & 0,91 & 0,80 \\
\hline 4 & & & & 0,91 & 0,92 & 0,84 \\
\hline 5 & & & & & 0,92 & 0,85 \\
\hline 6 & & & & & & 0,86 \\
\hline
\end{tabular}

\section{AGRADECIMENTOS}

O primeiro autor agradece pela concessão de bolsa de estudos do Consórcio Brasileiro de Pesquisa e Desenvolvimento do Café. Os autores agradecem aos alunos de Pós-Graduação da UFLA, que atuaram como avaliadores na validação da escala.

\section{REFERÊNCIAS BIBLIOGRÁFICAS}

Angelotti F, Scapin CR, Tessmann DJ, Vida JB, Oliveira RR, Canteri MG (2009) Diagrammatic scale for assessment of grapevine rust. Tropical Plant Pathology 33:439-443.

Boerema GH, Gruyter J, Noordeloos ME, Hamers MEC (2004) Phoma identification manual: differentiation of specific and intraspecific taxa in culture. Wallingford. CAB International.

Godoy CV, Carneiro SMT, Iamuti MT, Dalla Pria M, Amorim L, Berger RD, Bergamin Filho A (1997). Diagrammatic scale for bean diseases: development and validation. Zeitschrift für Pfanzenkrankheiten und Pflanzenschutz 104:336-345.

Gomes AMA, Michereff SJ, Mariano RLR (2004) Elaboração e validação de escala diagramática para cercosporiose da alface. Summa Phytopathologica 30:38-42.

Horsfall JG, Cowling EB (1978) Pathometry: the measurement of plant disease. In: Horsfall JG, Cowling EB (Eds.) Plant Disease: an advanced treatise how disease develops in populations. New York NY. Academic Press. pp. 119-136.

Leite RMVBC, Amorim L (2002) Elaboração e validação de escala diagramática para mancha de Alternaria em girassol. Summa Phytopatologica 28:14-19.

Madden LV, Hughes G, van den Bosch F (2007) The study of plant disease epidemics. Saint Paul MN. APS Press.

Martins MC, Guerzoni RA, Câmara GMS, Mattiazzi P, Lourenço SA, Amorim L (2004) Escala diagramática para avaliação do complexo de doenças foliares de final de ciclo em soja. Fitopatologia Brasileira 29:179-184.

Michereff SJ, Andrade DEGT, Noronha MA (2006). Elaboração e validação de escala diagramática para avaliação da severidade do carvão da folha do caupi. Summa Phytopathologica 32:5156 .

Nascimento ARP, Michereff SJ, Mariano RLR, Gomes AMA (2005). Elaboração e validação de escala diagramática para cancro bacteriano da videira. Summa Phytopathologica 31:59-64.

Nutter Junior FW, Schultz PM (1995) Improving the accuracy and precision of disease assessments: selection of methods and use of computer-aided training programs. Canadian Journal of Plant Pathology 17:174-184.

Oliveira CA, Pozza EA, Oliveira VB, Santos RC, Chaves ZM (2001) Escala diagramática para avaliação de cercosporiose em folhas de cafeeiro. Anais, II. Simpósio de Pesquisa dos Cafés do Brasil. Vitória ES. p. 80. Resumo 
Salgado M, Pfenning LH (2000) Identificação e caracterização morfológica de espécies de Phoma do Brasil. Anais, I. Simpósio de Pesquisa dos Cafés do Brasil. Poços de Caldas MG. pp. 183186. (Resumo Expandido)

Salgado M, Pozza EA, Pfenning LH, Berger RD (2002) Influencia da temperatura e do tempo de incubação no crescimento micelial e produção de conídios in vitro de espécies de Phoma do cafeeiro. Fitopatologia Brasileira 27 (Supl.):159.
Spósito MB, Amorim L, Belasque Júnior J, Bassanezi RB, Aquino R (2004) Elaboração e validação de escala diagramática para avaliação da severidade de mancha preta em frutos cítricos. Fitopatologia Brasileira 29:81-85.

Stewart RW (1957) Leaf blight and stem dieback of coffee caused by an undescribed species of Ascochyta. Mycologia 49:430-433.

TPP 8046 - Recebido 23 Abril 2008

Versão corrigida recebida 22 Junho 2009 - Aceito 21 Dezembro 2009 Editor de Seção: Lilian Amorim 